\title{
VARIABILIDADE ESPACIAL DA SODICIDADE EM RAMPAS CULTIVADAS COM GRAMÍNEAS PARA TRATAMENTO DE ESGOTO SANITÁRIO
}

\author{
Rodrigo Nogueira Martins ${ }^{1}$ \\ Ana Paula Ferreira Colares ${ }^{2}$ \\ Rodrigo Nobre Santana ${ }^{3}$ \\ Marcus Vinícius Araújo Marques ${ }^{4}$ \\ Danilo Pereira Ribeiro ${ }^{5}$
}

Resumo: O presente trabalho teve por objetivo avaliar a variabilidade espacial da sodicidade do solo em rampas cultivadas com Brachiaria humidicula e Zoysia japonica para tratamento de esgoto sanitário. Na estação de tratamento de esgoto do município de Januária/MG foram coletadas amostras de solo em duas rampas de tratamento de esgoto, uma cultivada com Brachiaria humidicula $(R C B H)$ e outra cultivada com Zoysia japonica (RCZJ). Foram realizadas análises de químicas do solo e com isso determinou-se a Razão de Adsorção de Sódio (RAS) e a Porcentagem de Sódio Trocável (PST). Os dados foram submetidos à geoestatística. As maiores variabilidades foram observadas para a RAS e PST da RCBH, sendo classificadas como elevadas. Na análise da dependência espacial foi possivel observar que as variáveis estudadas apresentam forte correlação espacial, com excessão da RAS obtida da RCZJ que é considerada de fraca. Apesar da alta variabilidade espacial, a amplitude dos valores de RAS e PST encontrados nas rampas são pequenas não apresentando grandes riscos a salinização do solo a curto prazo.

Palavras-chave: Salinidade; Sódio; Escoamento Superficial.

\footnotetext{
${ }^{1}$ Engenharia Agrícola e Ambiental / Instituto Federal do Norte de Minas Gerais - IFNMG Campus Januária. Brasil. E-mail: Rodrigonmartins@hotmail.com.

2 Engenharia Agrícola e Ambiental / Instituto Federal do Norte de Minas Gerais - IFNMG Campus Januária. Brasil. E-mail: anapaula.colares@hotmail.com.

3 Engenharia Agrícola e Ambiental / Instituto Federal do Norte de Minas Gerais - IFNMG Campus Januária. Brasil. E-mail: rodrigotidm@yahoo.com.br.

${ }^{4}$ Engenharia Agrícola e Ambiental / Instituto Federal do Norte de Minas Gerais - IFNMG Campus Januária. Brasil. E-mail: marcus.ifnmg@yahoo.com.br.

5 Dsc. Engenharia Agrícola / Instituto Federal do Norte de Minas Gerais - IFNMG Campus Januária. Brasil. Email: danilo.ribeiro@ifnmg.edu.br.
} 